\title{
Curcumol increases the sensitivity of colon cancer to 5-FU by regulating Wnt/ $\beta$-catenin signaling
}

\author{
Jinfeng Gao ${ }^{1}$, Daorong Hou ${ }^{2}$, Ping $\mathrm{Hu}^{1}$, Guoxin $\mathrm{Mao}^{3}$ \\ ${ }^{1}$ Department of Oncology, Affiliated Nanjing Jiangbei Hospital to Nantong University, Nanjing, China; ${ }^{2}$ Animal Core Facility, Nanjing Medical \\ University, Nanjing, China; ${ }^{3}$ Department of Chemotherapy, Affiliated Hospital of Nantong University, Nantong, China \\ Contributions: (I) Conception and design: J Gao, G Mao; (II) Administrative support: None; (III) Provision of study materials or patients: None; \\ (IV) Collection and assembly of data: D Hou, P Hu; (V) Data analysis and interpretation: G Mao; (VI) Manuscript writing: All authors; (VII) Final \\ approval of manuscript: All authors. \\ Correspondence to: Guoxin Mao. Department of Chemotherapy, Affiliated Hospital of Nantong University, 20 Xisi Road, Nantong 226001, China. \\ Email: maoguoxin2021@163.com.
}

Background: 5-fluorouracil (5-FU) resistance is the leading cause of treatment failure in colon cancer. Combination therapy is an effective strategy to inhibit cancer cells and prevent drug resistance. Therefore, we studied the antitumor effect of curcumol alone or combined with 5-FU on human colon cancer drugresistant cells.

Methods: The 5-FU resistant HCT116 cell line (HCT116/5-FU) was established by repeated exposure to gradually increasing concentrations of 5-FU; Cell viability was measured by cell counting kit-8 (CCK8); apoptosis rate of HCT116 cells was detected using Annexin V-fluorescein isothiocyanate (FITC) assay kit; cell proliferation and invasion were detected using colony formation assays, wound healing assay and transwell invasion assays; activity of transplanted tumor in vivo in specific pathogen free (SPF) BALB/c nude mice ( 6 weeks old, male) was monitored by bioluminescence imaging, immunohistochemistry and western blot analysis.

Results: Our study showed the potent antitumor effect of curcumol by induction of apoptosis, inhibition of proliferation, invasion, migration, and improvement of the therapeutic efficacy of 5-FU toward human colon cancer HCT116 cells. From our results, curcumol could chemosensitize 5-FU-resistant HCT116 cells. The combination of curcumol and 5-FU exerted a synergistic inhibitory effect on the induction of apoptosis. Also, this combination inhibited the proliferation, invasion, and migration of both chemo-resistant and sensitive cells. Curcumol treatment decreased multidrug resistance-associated protein 2 (MRP-2), P-glycoprotein (P-gp), survivin, and $\beta$-catenin expression, which correlated with multidrug resistance (MDR) and the target genes of $\mathrm{Wnt} / \beta$-catenin. It significantly increased the p- $\beta$-catenin level and Bad/Bcl-2 ratio in HCT116/5FU cells compared with 5-FU treatment. In vivo, curcumol significantly inhibited the growth of transplanted tumors and the expression of Ki-67, proliferating cell nuclear antigen (PCNA), and vascular endothelial growth factor (VEGF) in colon cancer cells.

Conclusions: Curcumol as a potential chemotherapeutic agent combined with 5-FU can overcome colon cancer resistance.

Keywords: Colon cancer; curcumol; 5 -fluorouracil resistance (5-FU resistance); Wnt/ $\beta$-catenin

Submitted Apr 02, 2021. Accepted for publication May 06, 2021.

doi: $10.21037 /$ tcr-21-689

View this article at: http://dx.doi.org/10.21037/tcr-21-689 


\section{Introduction}

Colon cancer is the third most frequently diagnosed cancer type globally, with over 1.2 million new cases and 600 thousand deaths yearly (1). The incidence rate of colon cancer increases with age and is higher in Europe, North America, and Africa (2), and chemotherapy plays a vital role in treating colon cancer (3). Although various chemotherapy drugs have been shown to improve the survival rate and quality of life of patients with colon cancer (4), after 30 years of clinical research, 5-fluorouracil (5-FU) is still the preferred drug $(5,6)$; however, the emergence of multidrug resistance (MDR) often leads to the treatment failure and death of patients with colon cancer (7). MDR in cancer refers to cancer resistance to various chemotherapy drugs with unrelated structures and functions after exposure to a single cytotoxic compound (8). A potent drug with the fewest side effects must be identified to reverse the effect of MDR and improve chemotherapy's efficacy toward multidrug-resistant tumors (9-11). Reversal of acquired resistance to 5 -FU is still a promising method to improve patients' prognosis with colorectal cancer.

Natural products have become one of the primary sources of anticancer drug discovery due to their excellent chemical diversity and low toxicity $(12,13)$. Natural products are still the subject of many drug discovery studies (14). Analyses of the quantity and source of chemotherapeutic drugs showed that approximately $60 \%$ of the approved drugs were derived from natural compounds $(13,15)$. Curcumol, a guaiacene sesquiterpene, was isolated from the root of Rhizoma Curcumae (16). Due to the low side effects of curcumol, many studies have focused on its biological activity $(17,18)$. Previous studies have also shown curcumol has anti-liver fibrosis, anti-proliferative, anti-inflammatory, antioxidant, and antibacterial activities $(19,20)$. Also, curcumol inhibits human cancer cells' growth and promotes the apoptosis of various cancer cells, including cervical cancer, breast cancer, lung cancer, gastric cancer, and liver cancer (21-24). Also, curcumol has been reported to increase cancer cells' sensitivity to adriamycin $(25,26)$. As far as we know, there is no published research on the drug resistance of curcumol to colon cancer and its mechanism. Therefore, we wondered whether curcumol combined with chemotherapy could increase the anticancer effects.

In this study, we investigated the combined effect of curcumol and 5-FU on colon cancer cells, besides the underlying mechanisms. Curcumol enhanced the chemotherapeutic effect of 5 -FU on colon cancer cells by regulating the $\mathrm{Wnt} / \beta$-catenin signaling pathway. These findings provide evidence for the application of curcumol in the clinical chemotherapy of colon cancer. We present the following article in accordance with the ARRIVE reporting checklist (available at http://dx.doi.org/10.21037/tcr-21-689).

\section{Methods}

\section{Cell culture}

HCT116 cells were obtained from the Type Culture Collection of the Chinese Academy of Sciences (Shanghai, China). Cells were cultured in Dulbecco's modified Eagle's medium (DMEM, HyClone, USA) supplemented with $10 \%$ fetal bovine serum (FBS, Gibco, USA), $100 \mu \mathrm{g} / \mathrm{mL}$ streptomycin, and $100 \mathrm{U} / \mathrm{mL}$ penicillin (HyClone). All cells were maintained at $37^{\circ} \mathrm{C}$ in a cell incubator containing $5 \%$ $\mathrm{CO}_{2}$. All cells were negative for contamination with other human cells and mycoplasma.

\section{Establishment of 5-FU-resistant HCT116 cells (HCT116/5-FU)}

Repeated exposure established 5-FU resistant HCT116 cell lines to accumulating concentrations of 5-FU (from 1 to $25 \mu \mathrm{M}$, cat. no. HY-9006, MedChemExpress) for five months (27). The cells were cultured in DMEM supplemented with $10 \% \mathrm{FBS}$ in a $37{ }^{\circ} \mathrm{C}$ incubator containing $5 \% \mathrm{CO}_{2}$. The medium was replaced three times a week and passaged using $0.125 \%$ trypsin/EDTA (ethylenediaminetetraacetic acid). Then, 5-FU resistant cells were placed in a complete medium containing $25 \mu \mathrm{M}$ 5-FU to maintain the 5-FU resistance (25).

\section{Cell viability}

Cell counting kit-8 detected cell viability (CCK-8, cat. No. HY-K0301, MedChemExpress). Curcumol displayed substantial solubility in $1 \%$ DMSO and was not toxic to HCT116 cells (28). After treatment with different concentrations $(0,10,20,30,40$ and $50 \mu \mathrm{g} / \mathrm{mL})$ of curcumol (cat. no. 100185-200506, MedChemExpress), cells were collected and seeded into 96 well plates at a density of $2 \times 10^{5}$ cells / $\mathrm{mL}$. Curcumol $(0 \mu \mathrm{g} / \mathrm{mL})$ was set as control group ( $\mathrm{n}=6)$. The cells were cultured at $37^{\circ} \mathrm{C}$ in $5 \% \mathrm{CO}_{2}$. After 48 hours, 10 $\mu \mathrm{L}$ of CCK- 8 reagent were added to each well, incubated for one hour, and the absorption value was detected at $450 \mathrm{~nm}$. All experiments were repeated three times. 


\section{Cell apoptosis detection}

An Annexin V-fluorescein isothiocyanate (FITC) detection kit (cat. no. 556547; BD Biosciences) was used to detect the apoptosis rate of HCT116 cells. Fresh medium containing curcumol $(30 \mu \mathrm{g} / \mathrm{mL})$ and $5-\mathrm{FU}(20 \mu \mathrm{M})(29)$ alone or combined was added to the corresponding well for $24 \mathrm{~h}$. HCT116 cells treated without curcumol or $5-\mathrm{FU}$ were set as control $(n=6)$. The cells were washed 2 times with cold PBS and then resuspended in $500 \mu \mathrm{L}$ of binding buffer. Subsequently, $5 \mu \mathrm{L}$ of Annexin V-FITC and $5 \mu \mathrm{L}$ of PI staining solution were added, the cells were rotated, cultured in the dark for 15 minutes, and detected using flow cytometry (BD FACSCalibur, BD Biosciences, USA). Annexin V/PI double staining's average fluorescence intensity was analyzed using FlowJo software (version 10.4.2, FlowJo LLC). The percentage of Annexin $\mathrm{V}^{+}$-FITC cells defined as the proportion of mortality.

\section{Colony formation assays}

The cells were cultured in $6 \mathrm{~cm}$ culture dishes $\left(1 \times 10^{3}\right.$ cells/dish) for 24 hours and then treated with curcumol $(30 \mu \mathrm{g} / \mathrm{mL})$ and 5 -FU $(20 \mu \mathrm{m})$ alone or in combination for two weeks $(n=6)$. The colonies were washed with PBS, fixed with methanol and stained with crystal violet for 15 minutes, washed slowly, and dried. The number of cell colonies was measured using software ImageJ 1.42.

\section{Wound bealing assay}

The motility of HCT116 cells was detected by performing a scratch wound assay. HCT 116 cells $\left(1 \times 10^{5} / \mathrm{mL}\right)$ were cultured overnight in 6-well plates. Then the cell monolayer was carefully scratched with a yellow pipette and washed with DMEM to remove cell debris. A fresh medium containing curcumol $(30 \mu \mathrm{g} / \mathrm{mL})$ and 5 -FU $(20 \mu \mathrm{m})$ alone or combined was added to the corresponding well for 24 hours $(\mathrm{n}=6)$. At $0,24,48$, and 72 hours, the scratch wound in each well was photographed with an Olympus IX-71 microscope. The motility of cells was determined by calculating the number of migrating cells.

\section{Transwell invasion assays}

Transwell chambers (Corning) were used to detect the migration of HCT116 cells. Briefly, cells pretreated with curcumol $(30 \mu \mathrm{g} / \mathrm{mL})$ or $5-\mathrm{FU}(20 \mu \mathrm{M})$ were trypsinized and resuspended in a medium lacking FBS $(\mathrm{n}=6) .1 \times 10^{5}$ cells were added to the upper chamber, while $600 \mu \mathrm{L}$ of medium supplemented with $50 \%$ FBS were added to the lower chamber. After 30 hours of culture, the invasive cells were stained with crystal violet and photographed with an Olympus IX-71 microscope.

\section{Establishment of tumor xenografts in nude mice}

All experiments with animals were approved by the Institutional Animal Care and Use Committee (IACUC) of the Nanjing Medical University, and were carried out following the approved guidelines. Specific Pathogen Free (SPF) BALB/c nude mice (6 weeks old, male, 18-22 g) were purchased from Nanjing medical university, and housed in steel micro isolator cages at $22{ }^{\circ} \mathrm{C}$ on a $12 / 12$ hours light/ dark cycle and freely received standard mouse chow and tap water in SPF facility in Nanjing Medical University. The tumor model was established in nude mice by subcutaneous implantation. mCherry-labeled HCT116 cells and HCT116/5-FU cells in logarithmic phase were digested with trypsin, rinsed three times with $1 \times$ PBS, and then suspended in $100 \mu \mathrm{L}$ of $1 \times$ PBS. Six nude mice (6 weeks old, male) were subcutaneously inoculated with $5 \times 10^{6}$ cells. The tumor transplantation experiment was divided into two parts. The order of treatment and measurement was set with a random number table to minimize potential confidants. In part I, after tumor palpability, xenograft-bearing mice was randomly divided into four groups with random number table ( $\mathrm{n}=6)$ : (I) the vehicle control (DMSO) plus HCT116 cells (20 mg/kg every other day, ip); (II) curcumol treatment plus HCT116 cells (20 mg/kg every other day, ip) (23); (III) 5 -FU treatment plus HCT116 cells $(35 \mathrm{mg} / \mathrm{kg}$ twice weekly, ip) (29); and (IV) curcumol (20 mg/kg every other day) and $5-\mathrm{FU}$ (35 mg/kg twice weekly, ip) cotreatment plus HCT116 cells. In part II, HCT116 cells and HCT116/5FU cells were subcutaneously inoculated into mice to establish a xenograft tumor model in nude mice. After tumor palpability, xenograft mice were then divided into four groups with random number table $(\mathrm{n}=6)$ : (I) vehicle control (DMSO) plus HCT116 cells $(20 \mathrm{mg} / \mathrm{kg}$ every other day); (II) vehicle control (DMSO) plus HCT116/5-FU cells $(20 \mathrm{mg} / \mathrm{kg}$ every other day, ip); (III) 5 -FU treatment plus HCT116/5-FU cells (35 mg/kg twice weekly, ip); and (IV) curcumol (20 mg/kg every other day, ip) and 5-FU (35 mg/kg twice weekly, ip) cotreatment plus HCT116/5FU cells. Tumor growth was measured weekly using bioluminescence imaging and calculated using the formula: 
$0.5 \times$ length $\times$ width $^{2}$ until the fourth week. The tumors were collected after mice were sacrificed under general anesthesia using intraperitoneal injection of pentobarbital sodium $(150 \mathrm{mg} / \mathrm{kg})$.

\section{Immunobistochemistry}

The tumor tissue was fixed with $4 \%$ paraformaldehyde, embedded in paraffin and cut into $4 \mu \mathrm{m}$ sections. Endogenous peroxidases were blocked with 3\% hydrogen peroxide, and the antigens were recovered in the citrate buffer at $\mathrm{pH}$ 6.0. Then, the sections were incubated with an anti-Ki-67 antibody (cat. No, ab16667, Abcam Biotechnology, Inc.), anti-proliferating cell nuclear antigen (PCNA) antibody (cat. No, ab92552, Abcam Biotechnology, Inc.), and anti-vascular endothelial growth factor (VEGF) antibody (cat. No, ab32152, Abcam Biotechnology, Inc.) at $4{ }^{\circ} \mathrm{C}$ overnight $(\mathrm{n}=6)$. Goat anti-mouse IgG (Abcam Biotechnology) was incubated with the section at $37^{\circ} \mathrm{C}$ for 1 hour. Tissue staining was detected under a light microscope (1-71, Olympus, Inc.), and protein expression was quantified using ImageJ software.

\section{Western blotting}

The cells were lysed in a RIPA lysis buffer containing $1 \mathrm{mM}$ phenylmethylsulfonyl fluoride (Bioteke Company). Protein samples $(50 \mu \mathrm{g})$ were separated on a $10 \%$ SDS-PAGE gel and transferred to nitrocellulose membranes. TBST buffer $(100 \mathrm{mM} \mathrm{NaCl}, 10 \mathrm{~mm}$ Tris $\mathrm{HCl}, \mathrm{pH} 7.4$, and $0.1 \%$ Tween 20) containing 5\% skim milk was used to block the membrane at $25{ }^{\circ} \mathrm{C}$ for 1 hour. Then, the membrane was incubated with primary antibodies against Bad (1:1,000, cat. No, ab32445, Abcam Biotechnology, Inc.), Bcl-2 (1:1,000, cat. No, ab182858, Abcam Biotechnology, Inc.), MRP-2 (1:1,000, cat. No, ab172630, Abcam Biotechnology, Inc.), P-gp (1:1,000, cat. No, ab234884, Abcam Biotechnology, Inc.), survivin (1:1,000, cat. No, ab76424, Abcam Biotechnology, Inc.), $\beta$-Catenin (1:1,000, cat. No, ab68183, Abcam Biotechnology, Inc.), p- $\beta$-catenin (1:1,000, cat. No, ab75777, Abcam Biotechnology, Inc.) and GAPDH (1:1,000, cat. no. sc-166574, Santa Cruz Biotechnology, Inc.) at $4{ }^{\circ} \mathrm{C}$ overnight. On the second day, an HRP-conjugated goat anti-rabbit IgG secondary antibody $(1: 5,000$, cat. no. sc2004; Santa Cruz Biotechnology, Inc.) or Goat anti-mouse IgG HRP binding secondary antibody $(1: 5,000$, cat. no. sc2005; Santa Cruz Biotechnology, Inc.) was incubated with the membrane for 1 hour at room temperature. Then, the membrane was rinsed three times with TBST. Western blot analyses were performed with Pierce ECL Western Blotting Substrate (cat. no. 32209; Thermo Fisher Scientific, Inc.) and ChemoDoc XRS ${ }^{+}$Molecular imager (Bio-Rad laboratory), and the quantitative analysis was performed with ImageJ software $(n=6)$.

\section{Statistical analysis}

Data are presented as the means \pm standard deviation (SD). Statistical analyses were performed using GraphPad 6.0 statistical software. Differences between groups were compared using a one-way analysis of variance (ANOVA). A $P$ value of $<0.05$ was considered significant.

\section{Results}

\section{Curcumol increases the sensitivity of colon cancer to 5-FU in vitro}

We first performed a CCK-8 assay to evaluate the cytotoxic effect of curcumol on the colon cancer cell line HCT116 and investigate whether curcumol increased colon cancer cells' sensitivity to 5 -FU (Figure $1 A$ ). At a $\leq 30 \mu \mathrm{g} / \mathrm{mL}$ concentration, no significant difference in the inhibition rate was observed between groups treated with curcumol. Then, we chose $30 \mu \mathrm{g} / \mathrm{mL}$ curcumol to test the effect of combination therapy with 5-FU. Flow cytometry analyses were performed to evaluate cell apoptosis. The combined treatment with curcumol and 5-FU significantly increased the cytotoxicity of 5-FU toward HCT116 cells compared with the other three groups (Figure 1B,C). A colony formation assay was conducted to investigate the tumorigenic potential of these cells. The colony formation capacity of HCT116 cells was reduced by the combined treatment with curcumol and 5-FU (Figure 1D,E).

We further evaluated the migration and invasion abilities of HCT116 cells by performing Transwell invasion assays and scratch migration assays. HCT116 cells were treated with curcumol and 5-FU alone or in combination, as indicated. As shown in Figure 1F, 5-FU significantly decreased colon cancer cells' invasion compared with control cells. Furthermore, the cotreatment more markedly inhibits cell invasion than the single treatment, suggesting that the antitumor activity of $5-\mathrm{FU}$ is enhanced by the addition of curcumol (Figure 1F,G). Also, the migration of HCT116 cells was assessed using scratch migration assay (Figure 1H). The cells were treated with curcumol and 
A

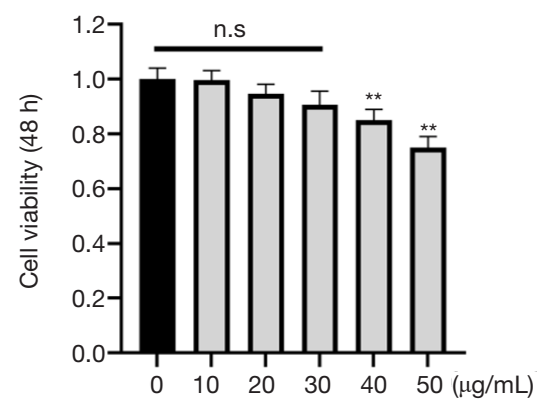

B

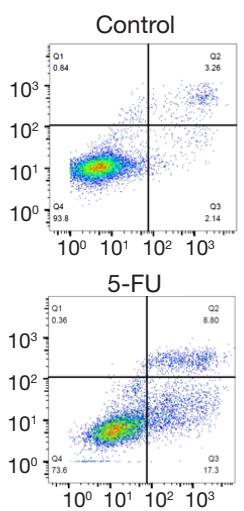

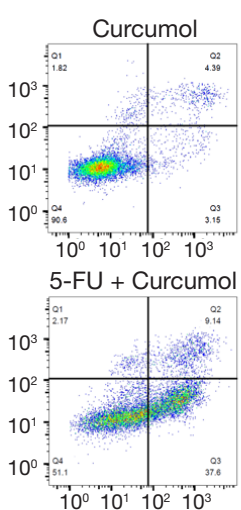

C

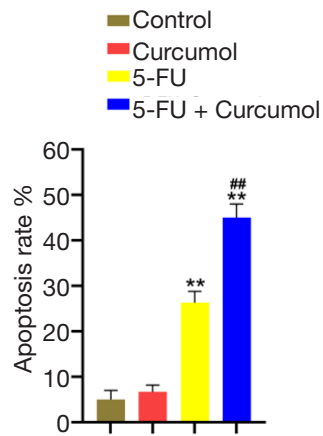

G

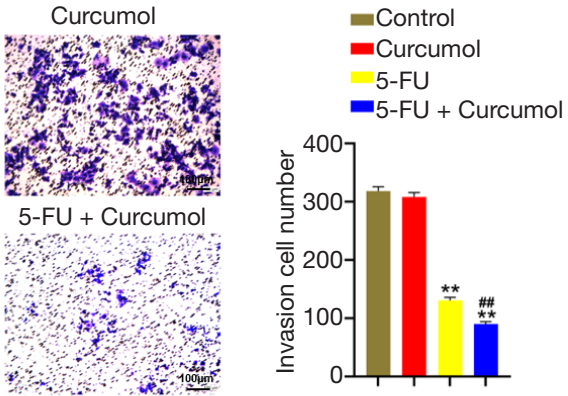

D

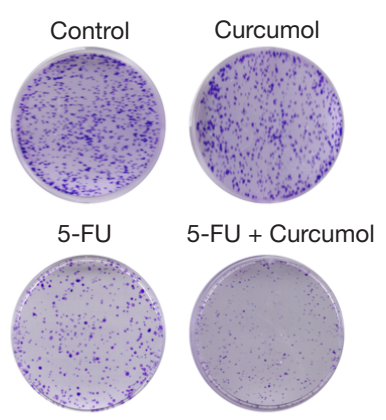

$\mathrm{H}$

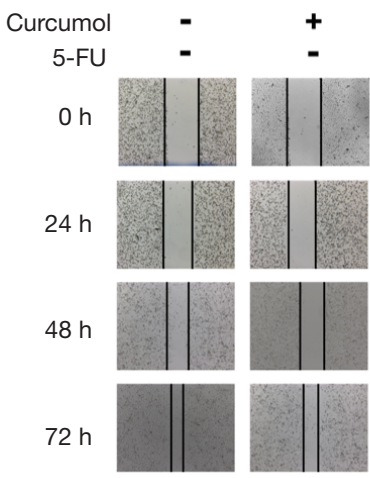

$\mathrm{E}$

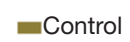
-Curcumol 5-FU

-5-FU + Curcumol

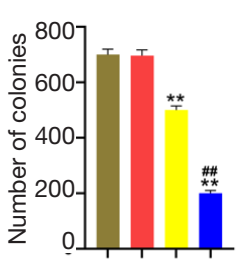

$\mathrm{F}$

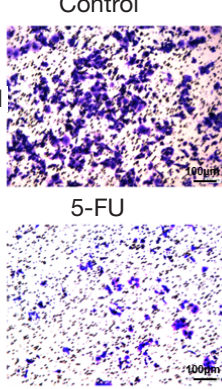


A

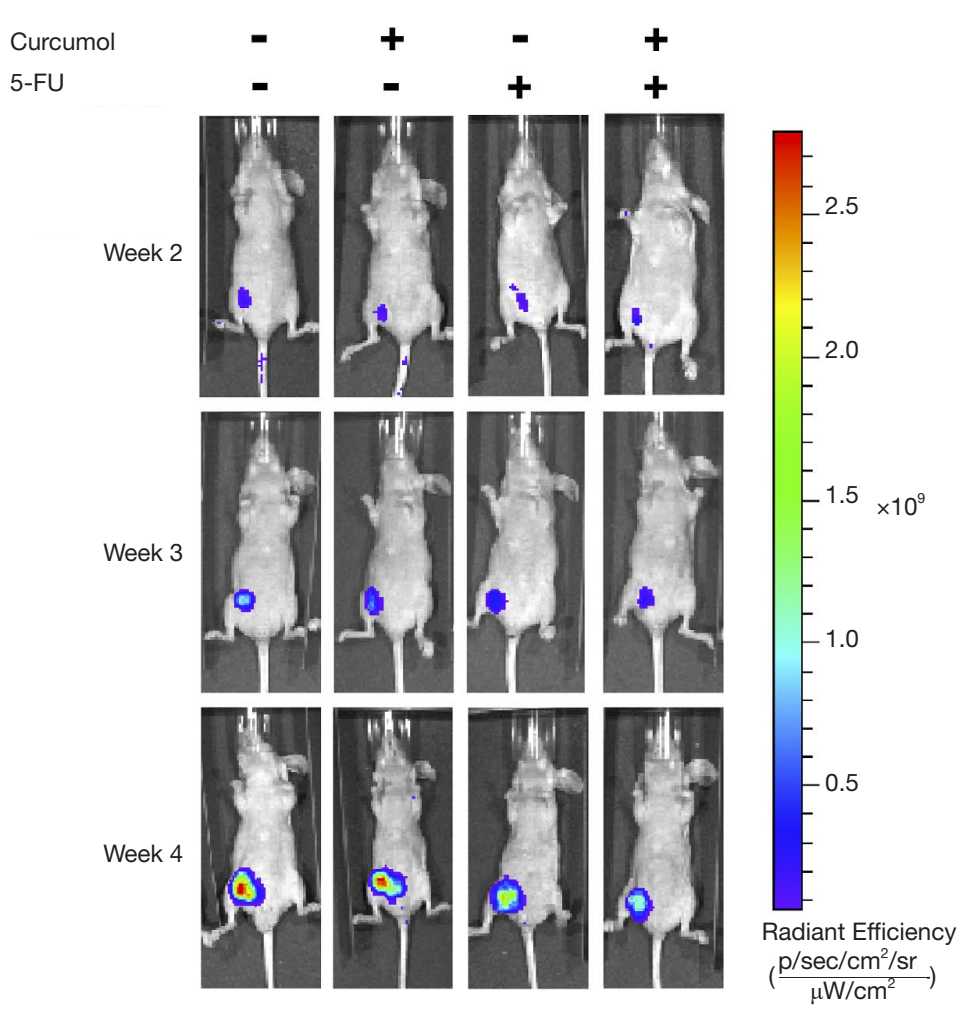

B

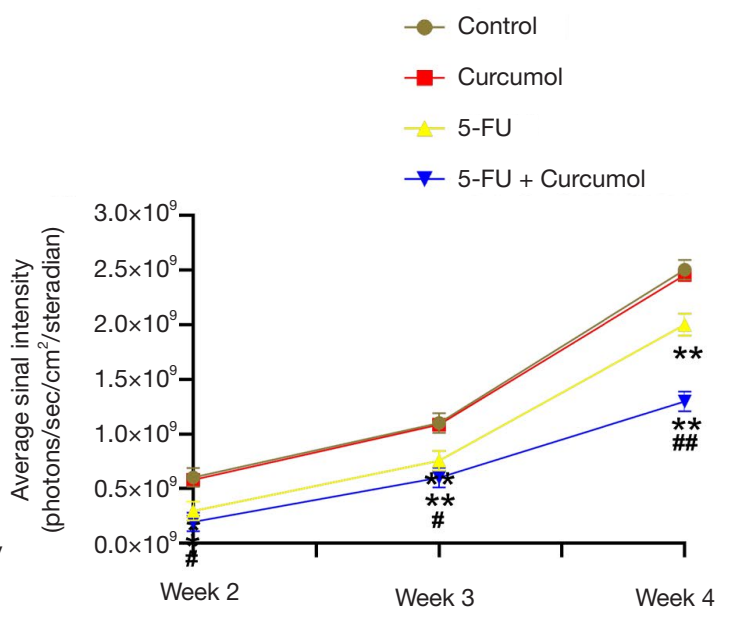

Figure 2 Curcumol increases the sensitivity of colon cancer to 5-FU in vivo. (A) In nude mice, representative bioluminescent images of tumors are shown; (B) the photon flux in bioluminescent images of tumors was quantified $(n=6)$. All experimental data are presented as the means \pm SD. Statistical significance: ${ }^{*} \mathrm{P}<0.05$ and ${ }^{* *} \mathrm{P}<0.01$ compared with the control group; ${ }^{*} \mathrm{P}<0.05$ and ${ }^{\# \prime \prime} \mathrm{P}<0.01$ compared with the $5-\mathrm{FU}$ group. 5-FU, 5-fluorouracil.

5 -FU alone or in combination for 24,48 , and 72 hours, as indicated. Compared with the Curcumol and 5-FU groups, the Curcumol+5-FU group presented markedly reduced cell mobility and cell migration (Figure 1I). Cell migration was more pronounced in the single treatment groups than in the Curcumol+5-FU group (Figure 17).

\section{Curcumol increases the sensitivity of colon cancer to 5-FU in vivo}

We established xenografts in nude mice using HCT116mCherry cells to explore further the effect of curcumol on the 5-FU sensitivity of colon cancer cells in vivo. Bioluminescence imaging showed treatment of curcumol and $5-\mathrm{FU}$ produced a significant decrease in the tumor size compared with the other groups (Figure $2 A, B$ ). From these results, curcumol increased the sensitivity of HCT116 cells to 5 -FU in vivo.

\section{Curcumol promotes the 5-FU sensitivity of HCT116/5-FU cells by modulating $W n t / \beta$-catenin signaling}

We have shown that 5-FU-induced HCT116 cell apoptosis is promoted by curcumol treatment. We explored the specific mechanism underlying this effect on HCT116/5FU cells. First, a 5-FU drug-resistant HCT116 cell line was established. The resistance of HCT116/5-FU cells to 5-FU was confirmed by exposing the cells with different concentrations of 5-FU ranging from 0 to $60 \mu \mathrm{M}$ (Figure 3A). Compared with the IC50 of HCT116 cells, the IC50 of HCT116/5-FU cells were significantly elevated (57.83 vs. $23.41 \mu \mathrm{M})$. Subsequently, flow cytometry analyses were used to evaluate cell apoptosis. No difference was observed between the HCT116/5-FU and HCT116/5FU+5-FU groups. The combined treatment with curcumol and 5-FU (HCT116/5-FU+5-FU+curcumol group) significantly enhanced the cytotoxicity of $5-\mathrm{FU}$ toward 
HCT116/5-FU cells compared with the other three groups (Figure 3B,C). We detected the main downstream effectors' protein expression in curcumol-mediated signaling cascade pathways using western blot analysis to elucidate further the potential molecular mechanism underlying this effect. We treated HCT116 or HCT116/5-FU cells with curcumol $(30 \mathrm{ng} / \mathrm{mL})$ and 5 -FU $(20 \mu \mathrm{mol} / \mathrm{L})$ alone or in combination for 24 hours. Compared with HCT116 and HCT116/5FU cell control treatment, the 5-FU treatment increased bad expression and decreased Bcl-2 expression and the bad/ Bcl-2 ratio in HCT116/5-FU cells (Figure 3D,E). However, bad protein expression was more substantially upregulated, and Bcl-2 protein expression was markedly downregulated in the 5-FU/curcumol-cotreated cells compared with the 5 -FU -treated cells. The Bad/Bcl-2 ratio was increased in the 5-FU/curcumol-cotreated cells (Figure 3D,E). Thus, curcumol treatment enhances 5-FU-induced cell apoptosis and is partially associated with the Bad/Bcl-2 pathway in colon cancer cells. The western blotting results also showed increased MRP-2, P-gp, survivin, and $\beta$-catenin levels and reduced p- $\beta$-catenin levels in the HCT116/5FU and HCT116/5-FU+5-FU groups compared with the HCT116 group (Figure 3D,F). Curcumol decreased MRP-2, P-gp, survivin, and $\beta$-catenin expression and significantly increased $\mathrm{p}-\beta$-catenin levels in HCT116/5-FU cells compared with the $5-\mathrm{FU}$ treatment. Together, these results indicated that curcumol influenced $5-\mathrm{FU}$ resistance through $W n t / \beta$-catenin signaling and downstream effectors in HCT116/5-FU cells.

\section{The curcumol enhanced 5-FU-mediated antitumor activation in a colon cancer xenograft model}

We established a nude mouse subcutaneous xenograft model using HCT116 and HCT116/5-FU cells to further evaluate the combined treatment efficacy with curcumol and 5-FU. Consistent with the results in vitro, the tumor volume of 5-FU - and curcumol combined treatment group was significantly smaller than that of single drug treatment and control group. However, the tumor volume was substantially reduced in the HCT116/5-FU+5-FU group compared with the HCT116/5-FU group (Figure 4A,B). The data further support the synergistic effect of curcumol and $5-\mathrm{FU}$.

The Ki-67, PCNA, and VEGF expression levels in the xenograft tumors were immunohistochemically evaluated, and the 5-FU and curcumol cotreatment group had the highest negative percentage among the four groups
(Figure $4 C, D$ ). The results were consistent with the results in vitro and further revealed curcumol treatment improves the antitumor efficacy of $5-\mathrm{FU}$, indicating that the synergistic effect was mediated by inactivation of Ki-67, PCNA, and VEGF in colon cancer cells.

\section{Discussion}

Colorectal cancer (CRC) is a leading cause of cancerrelated death worldwide (30-32). In recent years, due to the progress achieved in cancer treatment, the survival rate of patients with colorectal cancer has significantly improved (33). However, resistance to chemotherapeutic agents usually occurs during colorectal cancer treatment and promotes cancer progression $(34,35)$. The most common and standard anti-drug resistance strategy is to use other anticancer drugs, but it is not always effective in most patients due to MDR (36).

5 -FU is an essential drug used to treat colorectal cancer. However, MDR development is considered a significant obstacle in colon cancer treatment (37). Chemo-resistant cells have unlimited proliferation potential, are not affected by apoptosis, stimulate pathological angiogenesis, and promote metastatic disease progression. One way to overcome or delay the emergence of drug-resistant cancer cells is to combine drugs with different molecular mechanisms (38). The combination of natural polyphenols and anticancer drugs shows promising results, which are widely accepted by cancer researchers (39). At present, many studies have found that natural drug compounds extracted from plant extracts play an essential role in the treatment of human diseases (40), and they are an effective method to treat metastatic tumors $(41,42)$. The application of natural products in chemotherapy has been reported to improve chemotherapy effects (43-46). Due to their increased efficacy and minimal side effects, natural products are currently being reassessed in extensive studies of their therapeutic properties (47).

Curcumol, a pure monomer extracted from Rhizoma Curcumae, has recently been shown to exert antitumor effects on many cancer cells (48-52). Recently, curcumol was reported to exert a potential effect on adriamycin resistance in tumors $(25,26)$. In the present report, we showed the potent antitumor effect of curcumol by induction of apoptosis, inhibition of proliferation, invasion, migration, and improvement of the therapeutic efficiency of 5-FU in HCT116 cells. Curcumol treatment inhibits the $\beta$-catenin expression and increased $\mathrm{p}-\beta$-catenin level, thus inhibiting 

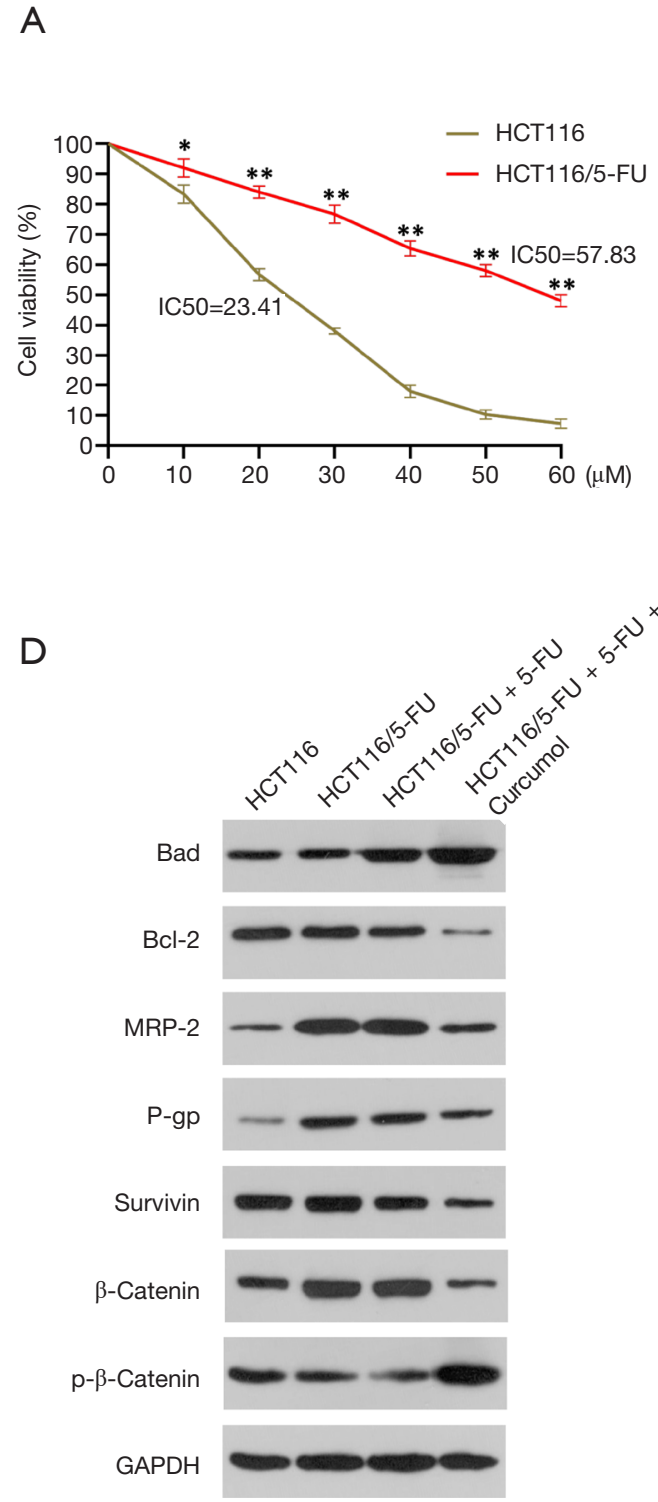

B

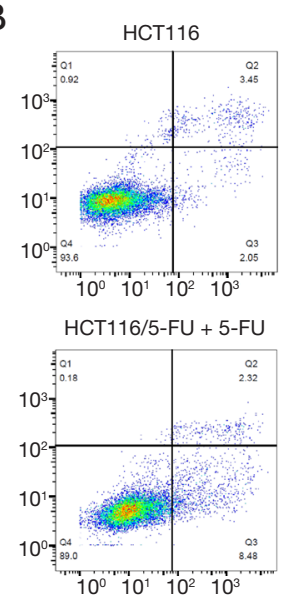

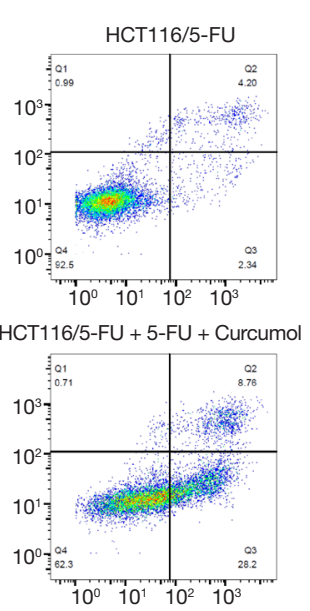

C
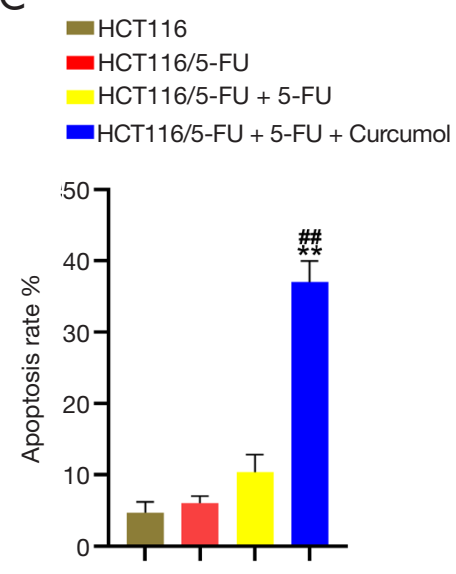

$E$

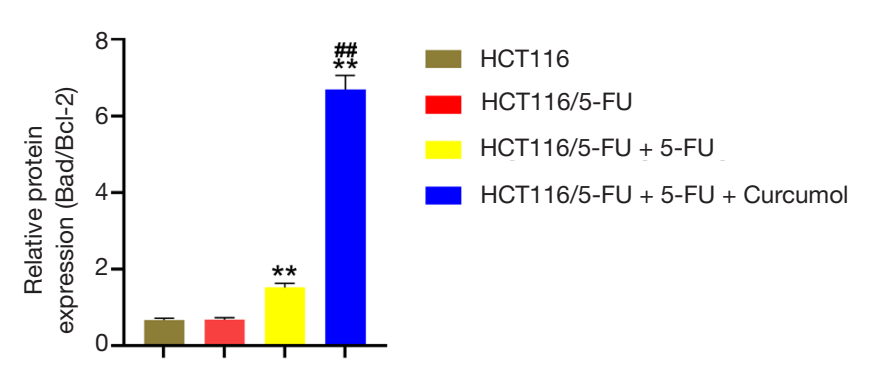

$\mathrm{F}$

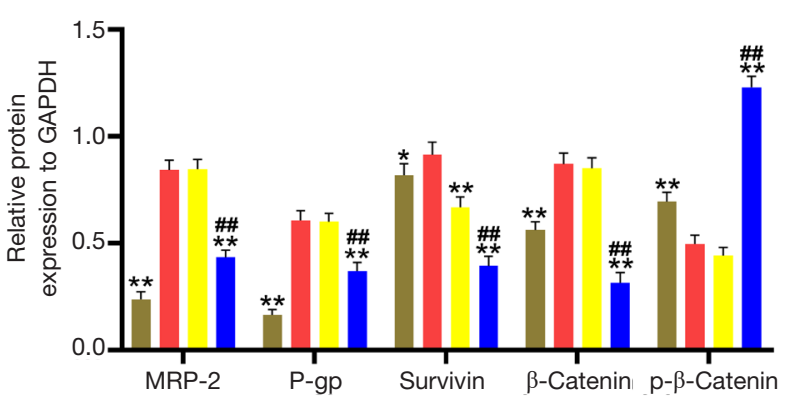

Figure 3 Curcumol increases the 5 -FU-sensitivity of HCT116/5-FU cells by modulating the $\mathrm{Wnt} / \beta$-catenin pathway. (A) Effects of 5 -FU (range from 0 to $60 \mu \mathrm{M}$ ) on HCT116 and HCT116/5-FU cell viability (n=6). (B) HCT116/5-FU cell apoptosis was detected 48 hours after treatment with curcumol $(30 \mu \mathrm{g} / \mathrm{mL})$ and/or 5-FU $(20 \mu \mathrm{M})$ using flow cytometry analysis $(\mathrm{n}=6)$. (C) Flow cytometry results are showed as quantitative bar graphs. Mortality was defined as the percentage of Annexin $\mathrm{V}+$ cells $(\mathrm{n}=6)$. (D) Representative western blots were depicting the levels of the Bad, Bcl-2, MRP-2, P-gp, Survivin, $\beta$-Catenin, and p- $\beta$-Catenin proteins in the indicated colon cancer cell lines. (E) The $\mathrm{Bad} / \mathrm{Bcl}-2$ ratio was quantitatively analyzed $(\mathrm{n}=6)$. (F) The protein expression levels were quantitatively analyzed $(\mathrm{n}=6)$. All experimental data are presented as the means $\pm \mathrm{SD}$. Statistical significance: ${ }^{*} \mathrm{P}<0.05$ and ${ }^{* *} \mathrm{P}<0.01$ compared with the HCT116/5-FU group; ${ }^{\# \#} \mathrm{P}<0.01$ compared with the HCT116/5-FU+5-FU group. IC50: the 50\% inhibitory concentration. 5-FU, 5-fluorouracil. 
A

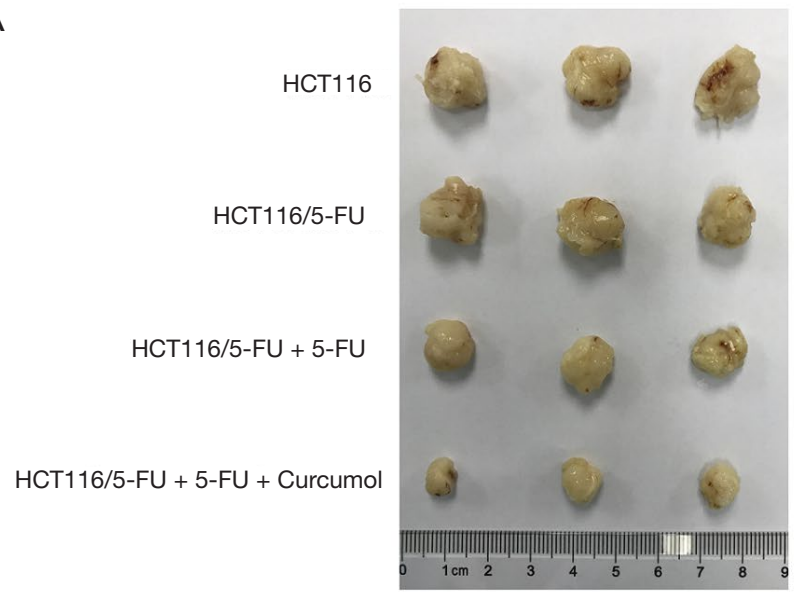

B

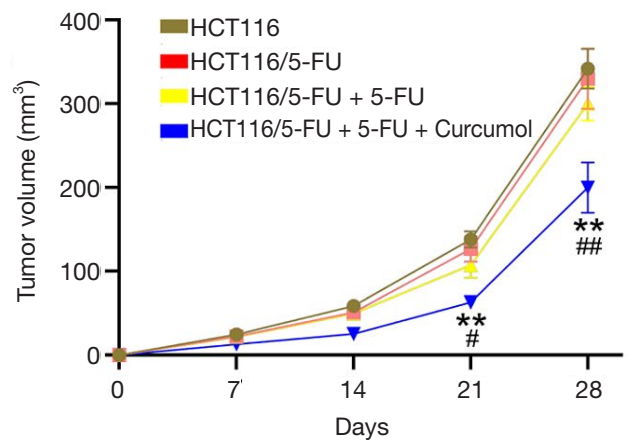

C
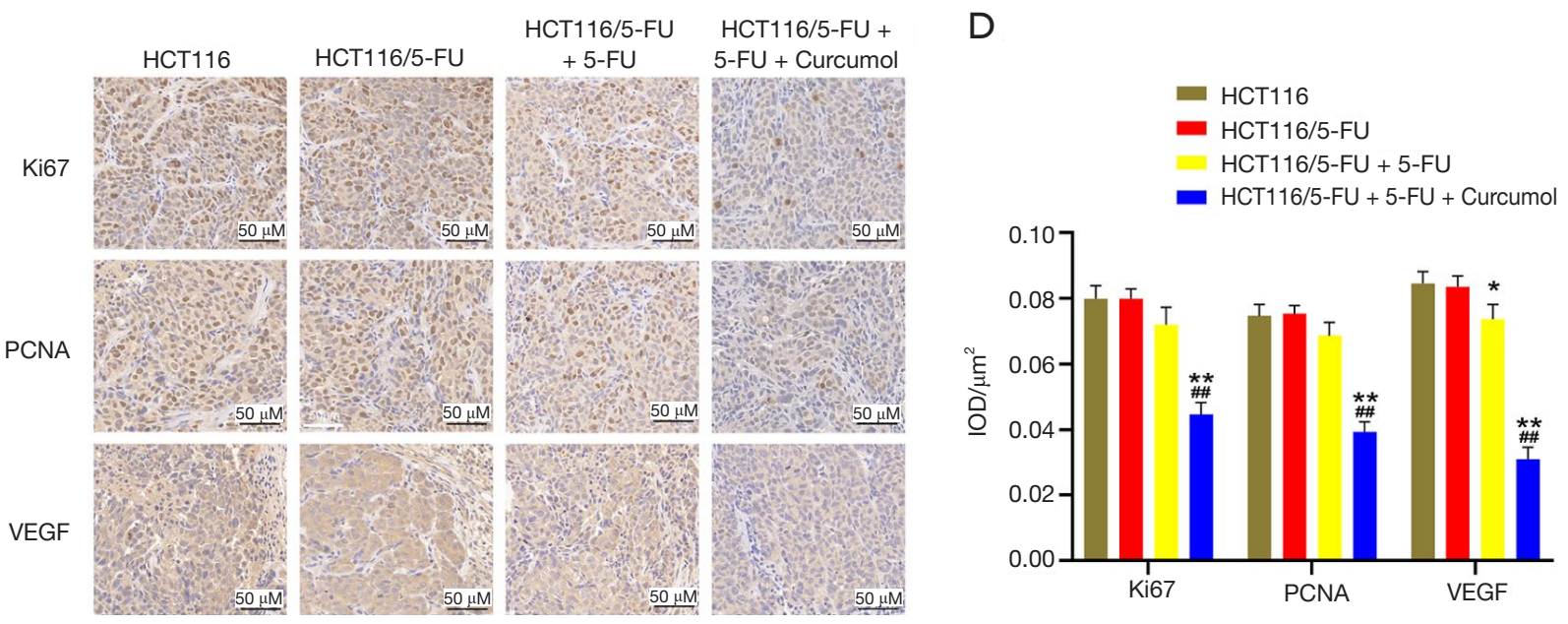

Figure 4 Curcumol increases the 5-FU-sensitivity of HCT116/5-FU cells in vivo. (A) The tumors from each mouse were excised and photographed. (B) The tumor volume was calculated using the formula $0.5 \times$ length $\times$ width2 $(\mathrm{n}=6)$. (C) The Ki67, PCNA, and VEGF expression levels in xenograft tumors were immunohistochemically evaluated. (D) The quantitative evaluation of Ki67, PCNA, and VEGF expression is presented as the $\mathrm{IOD} / \mathrm{\mu m}^{2}(\mathrm{n}=6)$. All experimental data are presented as the means $\pm \mathrm{SD}$. Statistical significance: ${ }^{*} \mathrm{P}<0.05$ and ${ }^{* *} \mathrm{P}<0.01$ compared with the HCT116/5-FU group; ${ }^{*} \mathrm{P}<0.05$ and ${ }^{\# \#} \mathrm{P}<0.01$ compared with the HCT116/5-FU+5-FU group. 5-FU, 5 -fluorouracil; PCNA, proliferating cell nuclear antigen; VEGF, vascular endothelial growth factor; IOD, integrated optical density.

P-gp, MRP2, survivin, and Bcl-2 are correlated with MDR and the target genes of $\mathrm{Wnt} / \beta$-catenin, compared with 5 -FU treatment in HCT116/5-FU cells. As shown in our present study, curcumol inhibits MDR in CRC. Consistent with our results, curcumol has been reported to inhibit Wnt/ $\beta$-catenin signaling in triple-negative breast cancer and lung adenocarcinoma $(53,54)$. Importantly, aberrant Wnt/ $\beta$-catenin signaling plays a critical role in the development and progression of various human malignancies, and mutations in this pathway's components are defining
CRC features $(30,55)$. The $W n t / \beta$-catenin pathway is closely related to colon cancer (56). According to previous studies, inactivation of the $\mathrm{Wnt} / \beta$-catenin signal is usually accompanied by antitumor effects, while activation of the $\mathrm{Wnt} / \beta$-catenin pathway leads to cancer development (57). Our study revealed that curcumol decreased the expression of $\beta$-catenin and increased the level of $p-\beta$-catenin. The combination of curcumol and 5-FU enhanced the inhibitory effects compared with treatment with 5-FU alone, suggesting that curcumol might play a role in regulating 
the $\mathrm{Wnt} / \beta$-catenin pathway in colon cancer. Inactivation of the $\mathrm{Wnt} / \beta$-catenin pathway mediates the suppression of cell growth and metastasis in various cancer types $(58,59)$. Therefore, curcumol might enhance the antitumor effects of 5 -FU by suppressing the $\mathrm{Wnt} / \beta$-catenin pathway.

A recognized hallmark of cancer cell survival and growth is aberrant activation of growth signaling pathways, including $W n t / \beta$-catenin signaling, which has become a valid target of antitumor therapy $(60,61)$. Wnt/ $\beta$-catenin signaling is involved in MDR, and its mechanisms includes mechanisms including membrane transport proteins (62), topoisomerases (63), abnormal DNA damage and repair, and changes in the tumor microenvironment (64). Several membrane transport proteins are involved in MDR, including $\mathrm{P}-\mathrm{gp}, \mathrm{MDR}$ proteins (MRPs), and breast cancer resistance protein (BCRP) $(65,66)$. Western blot analysis showed curcumol negatively regulated the Wnt/ $\beta$-catenin signaling pathway by suppressing $\beta$-catenin and increasing $\mathrm{p}-\beta$-catenin levels and subsequently decreasing the expression of the MRP-2, P-gp, and survivin proteins to inhibit the expression and nuclear translocation of $\beta$-catenin. When the canonical Wnt signaling pathway is inactivated, phosphorylated $\beta$-catenin is ubiquitinated and destroyed by the proteasome. This deactivation allows it to migrate to the nucleus and bind to TCF/LEF $(67,68)$. The resulting DNA-binding complex promotes the transcription of various genes involved in cancers, including MRP-2, P-gp, and survivin (69). Activation of the $\mathrm{Wnt} / \beta$-catenin signaling pathway promotes MRP-2 and P-gp expression (70). Previous studies have certified P-gp, MRP, survivin, and Bcl2 are target genes of $\mathrm{Wnt} / \beta$-catenin signaling $(71,72)$. The accumulation of $\beta$-catenin in cells is a crucial step triggering $W n t / \beta$-catenin target gene expression (73). One of the effective mechanisms of MDR is closely linked to ATPbinding cassette transporters (ABC transporters), including P-gp and MRP-2, which can pump multiple chemotherapy agents out of cells to attenuate drug-induced cytotoxicity (74,75). Overexpression of ABC transporters contributes to MDR in cancer cells $(76,77)$. $\mathrm{P}$-gp, a significant factor involved in MDR, is a membrane transport protein that expels cytotoxic drugs from the cell, decreasing intracellular drug levels and efficacy (78). MRP2 also mediates resistance to chemotherapeutic drugs (79) and may also mediate the efflux of the active drug metabolites from cancer cells (80). From our results, curcumol improved the drug sensitivity of HCT116 cancer cells by downregulating the expression of P-gp, MRP2, survivin, and Bcl-2 via its effects on $\beta$-catenin. Also, anti-apoptotic proteins contribute to
MDR (81). The overexpression of survivin and Bcl2 is often observed in a series of solid tumors, including CRC (56). The anticancer potential of curcumol has been declared to be linked to apoptosis induction via p53 regulation (82), the accumulation of ROS/oxidative stress (83), reduced expression of anti-apoptotic proteins (Bcl-2 and Bcl-xl) $(23,84)$, and increased expression of proapoptotic proteins (Bax and Bad) (23). The sustained high-level expression of anti-apoptotic proteins protects CRC cells from drug-induced apoptosis to mediate MDR $(85,86)$. In this study, in vivo experiments were carried out to confirm the results obtained in vitro. Ki-67, PCNA, and VEGF expression represent an index of cell proliferation (87). The administration of curcumol and 5-FU inhibited the expression of Ki-67, PCNA, and VEGF, which further confirmed the hypothesis that curcumol enhanced the effects of 5-FU on cell proliferation and apoptosis in the colon cancer cell line HCT116. Curcumol was found to exert an anti-proliferative effect on colorectal cancer in vivo (24). The development of more effective drugs to treat aberrant cell proliferation and apoptosis has been a promising chemotherapeutic strategy (88). In our study, the combination of curcumol and 5-FU enhanced the antitumor effect of 5-FU on inhibiting tumor growth, consistent with previous findings (89).

In conclusion, we demonstrated the anti-proliferative and antimetastatic effects of curcumol in vitro and in vivo. These inhibitory effects are mediated by the inhibition of $\mathrm{Wnt} / \beta$-catenin signaling, supporting using therapeutic approaches targeting $\mathrm{Wnt} / \beta$-catenin activity to prevent colon development and tumor metastasis. Altogether, curcumol might be a beneficial therapeutic agent for colon cancer treatment, although further studies are needed.

\section{Acknowledgments}

The authors would like to thank Dr. Bing Yao (Department of Genetics, Nanjing Medical University) for his technical assistance.

Funding: None.

\section{Footnote}

Reporting Checklist: The authors have completed the ARRIVE reporting checklist. Available at http://dx.doi. org/10.21037/tcr-21-689

Data Sharing Statement: Available at http://dx.doi. 
org/10.21037/tcr-21-689

Conflicts of Interest: All authors have completed the ICMJE uniform disclosure form m (available at http://dx.doi. org/10.21037/tcr-21-689). The authors have no conflicts of interest to declare.

Ethical Statement: The authors are accountable for all aspects of the work in ensuring that questions related to the accuracy or integrity of any part of the work are appropriately investigated and resolved. All experiments with animals were approved by the Institutional Animal Care and Use Committee (IACUC) of the Nanjing Medical University, and were carried out following the approved guidelines.

Open Access Statement: This is an Open Access article distributed in accordance with the Creative Commons Attribution-NonCommercial-NoDerivs 4.0 International License (CC BY-NC-ND 4.0), which permits the noncommercial replication and distribution of the article with the strict proviso that no changes or edits are made and the original work is properly cited (including links to both the formal publication through the relevant DOI and the license). See: https://creativecommons.org/licenses/by-nc-nd/4.0/.

\section{References}

1. Li LF, Chan RLY, Lu L, et al. Cigarette smoking and gastrointestinal diseases: the causal relationship and underlying molecular mechanisms. Int J Mol Med 2014;34:372-380.

2. Center MM, Jemal A, Smith RA, et al. Worldwide variations in colorectal cancer. CA Cancer J Clin 2009;59:366-78.

3. Webber EM, Kauffman TL, O'Connor E, et al. Systematic review of the predictive effect of MSI status in colorectal cancer patients undergoing 5-FU-based chemotherapy. BMC Cancer 2015;15:156.

4. Mármol I, Sánchez-de-Diego C, Pradilla Dieste A, et al. A General Overview and Future Perspectives in Colorectal Cancer. Int J Mol Sci 2017;18:197.

5. Borralho PM, Moreira da Silva I, Aranha MM, et al. Inhibition of Fas expression by RNAi modulates 5 -fluorouracilinduced apoptosis in HCT116 cells expressing wild-type $\mathrm{p} 53$. Biochimica et biophysica acta 2007;1772:40-7.

6. Chibaudel B, Tournigand C, Andre T, et al. Therapeutic strategy in unresectable metastatic colorectal cancer. Ther Adv Med Oncol 2012;4:75-89.

7. Xie Q, Wu MY, Zhang DX, et al. Synergistic anticancer effect of exogenous wild-type $\mathrm{p} 53$ gene combined with 5 -FU in human colon cancer resistant to 5 -FU in vivo. World J Gastroenterol 2016;22:7342-52.

8. Thomas H, Coley HM. Overcoming multidrug resistance in cancer: an update on the clinical strategy of inhibiting p-glycoprotein. Cancer Control 2003;10:159-65.

9. Zhao HD, Xie HJ, Li J, et al. Research progress on reversing multidrug resistance in tumors by using Chinese medicine. Chin J Integr Med 2018;24:474-80.

10. Temraz S, Mukherji D, Alameddine R, et al. Methods of overcoming treatment resistance in colorectal cancer. Crit Rev Oncol Hematol 2014;89:217-30.

11. Fong W, To KKW. Drug repurposing to overcome resistance to various therapies for colorectal cancer. Cell Mol Life Sci 2019;76:3383-406.

12. da Rocha AB, Lopes RM, S chwartsmann G. Natural products in anticancer therapy. Curr Opin Pharmacol 2001;1:364-9.

13. Mann J. Natural products in cancer chemotherapy: past, present and future. Nat Rev Cancer 2002;2:143-8.

14. Lee TK, Roh HS, Yu JS, et al. Pinecone of Pinus koraiensis Inducing Apoptosis in Human Lung Cancer Cells by Activating Caspase- 3 and its Chemical Constituents. Chem Biodivers 2017;14.

15. Cragg GM, Newman DJ, Snader KM. Natural products in drug discovery and development. J Nat Prod 1997;60:52-60.

16. Ding J, Wang JJ, Huang C, et al. Curcumol from Rhizoma Curcumae suppresses epileptic seizure by facilitation of GABA(a) receptors. Neuropharmacology 2014;81:244-55.

17. Wang J, Li X, Bai Z, et al. Curcumol induces cell cycle arrest in colon cancer cells via reactive oxygen species and Akt/GSK3ß/cyclin D1 pathway. J Ethnopharmacol 2018;210:1-9.

18. Wang J, Wu J, Li X, et al. Identification and validation nucleolin as a target of curcumol in nasopharyngeal carcinoma cells. Journal of Proteomics 2018;182:1-11.

19. Jiang $\mathrm{Y}$, Li ZS, Jiang FS, et al. Effects of different ingredients of zedoary on gene expression of HSC-T6 cells. World J Gastroenterol 2005;11:6780-6.

20. Dang YY, Li XC, Zhang QW, et al. Preparative isolation and purification of six volatile compounds from essential oil of Curcuma wenyujin using high-performance centrifugal partition chromatography. J Sep Sci 2010;33:1658-64.

21. Zhang W, Wang Z, Chen T. Curcumol induces apoptosis 
via caspases-independent mitochondrial pathway in human lung adenocarcinoma ASTC-a-1 cells. Medical oncology 2011;28:307-14.

22. Guo P, Wang YW, Weng BX, et al. Synthesis, anti-tumor activity, and structure-activity relationships of curcumol derivatives. J Asian Nat Prod Res 2014;16:53-8.

23. Cai F, Chen M, Zha D, et al. Curcumol potentiates celecoxib-induced growth inhibition and apoptosis in human non-small cell lung cancer. Oncotarget 2017;8:115526-45.

24. Liu H, Wang J, Tao Y, et al. Curcumol inhibits colorectal cancer proliferation by targeting miR-21 and modulated PTEN/PI3K/Akt pathways. Life Sci 2019;221:354-61.

25. Zeng C, Fan D, Xu Y, et al. Curcumol enhances the sensitivity of doxorubicin in triple-negative breast cancer via regulating the miR-181b-2-3p-ABCC3 axis. Biochem Pharmacol 2020;174:113795.

26. Zhong Z, Yu H, Wang S, et al. Anti-cancer effects of Rhizoma Curcumae against doxorubicin-resistant breast cancer cells. Chin Med 2018;13:44.

27. Takahashi K, Tanaka M, Inagaki A, et al. Establishment of a 5-fluorouracil-resistant triple-negative breast cancer cell line. Int J Oncol 2013;43:1985-91.

28. Zhang J, Su G, Tang Z, et al. Curcumol Exerts Anticancer Effect in Cholangiocarcinoma Cells via Down-Regulating CDKL3. Front Physiol 2018;9:234.

29. Li S, Tian J, Zhang H, et al. Down-regulating IL-6/ GP130 targets improved the anti-tumor effects of 5-fluorouracil in colon cancer. Apoptosis 2018;23:356-74.

30. Cunningham D, Atkin W, Lenz HJ, et al. Colorectal cancer. Lancet 2010;375:1030-47.

31. Labianca R, Beretta GD, Kildani B, et al. Colon cancer Crit Rev Oncol Hematol 2010;74:106-33.

32. Ragnhammar P, Hafstrom L Nygren P, et al. A systematic overview of chemotherapy effects in colorectal cancer. Acta Oncol 2001;40:282-308

33. Krisnamurti DGB, Louisa M, Anggraeni E, et al.Drug Efflux Transporters Are Overexpressed in Short-Term Tamoxifen-Induced MCF7 Breast Cancer Cells. Adv Pharmacol Sci 2016;2016:6702424.

34. Misale S, Yaeger R, Hobor S, et al. Emergence of KRAS mutations and acquired resistance to anti-EGFR therapy in colorectal cancer. Nature 2012;486:532-6.

35. Hugen N, Brown G, Glynne-Jones R, et al. Advances in the care of patients with mucinous colorectal cancer. Nat Rev Clin Oncol 2016;13:361-9.

36. Wang T, Chen Z, Zhu YF, et al. Inhibition of transient receptor potential channel 5 reverses 5 -Fluorouracil resistance in human colorectal cancer cells. J Biol Chem 2015;290:448-56.

37. Sartore-Bianchi A, Loupakis F, Argilés G, et al. Challenging chemoresistant metastatic colorectal cancer: therapeutic strategies from the clinic and from the laboratory. Ann Oncol 2016;27:1456-66.

38. Anreddy N, Gupta P, Kathawala R, et al. Tyrosine Kinase Inhibitors as Reversal Agents for ABC Transporter Mediated Drug Resistance. Molecules 2014;19:13848-77.

39. Cao J, Han, J, Xiao H, et al. Effect of Tea Polyphenol Compounds on Anticancer Drugs in Terms of Anti-Tumor Activity. Toxicology, and Pharmacokinetics. Nutrients 2016;8:762.

40. Park MN, Song HS, Kim M, et al. Review of Natural Product-Derived Compounds as Potent Antiglioblastoma Drugs. Biomed Res Int 2017;2017:8139848.

41. Wei Z, Shan Y, Tao L, et al. Diallyl trisulfides, a natural histone deacetylase inhibitor, attenuate HIF-1 $\alpha$ synthesis, and decreases breast cancer metastasis. Mol Carcinog 2017;56:2317-31

42. Silva IT, Geller FC, Persich L, et al. Cytotoxic effects of natural and semisynthetic cucurbitacins on lung cancer cell line A549. Invest New Drugs 2016;34:139-48.

43. Yuan R, Hou Y, Sun W, et al. Natural products to prevent drug resistance in cancer chemotherapy: a review. Ann N Y Acad Sci 2017;1401:19-27.

44. Bosch-Barrera J, Queralt B, Menendez J. Targeting STAT3 with silibinin to improve cancer therapeutics. Cancer Treat Rev 2017;58:61-9.

45. Engi H, Hohmann J, Gang G, et al. Chemoprevention and inhibition of P-glycoprotein in cancer cells by Chinese medicinal herbs. Phytother Res 2008;22:1671-6.

46. Kunnumakkara AB, Diagaradjane P, Guha S, et al. Curcumin sensitizes human colorectal cancer xenografts in nude mice to gamma-radiation by targeting nuclear factor-kappa B-regulated gene products. Clin Cancer Res 2008;14:2128-36.

47. Wang J, Huang FX, Bai Z, et al. Curcumol inhibits growth and induces apoptosis of colorectal cancer LoVo cell line via IGF-1R and p38 MAPK pathway. Int J Mol Sci 2015;16:19851-67.

48. Ning L, Ma H, Jiang ZY, et al. Curcumol Suppresses Breast Cancer Cell Metastasis by Inhibiting MMP-9 Via JNK1/2 and Akt-Dependent NF- B Signaling Pathways. Integr Cancer Ther 2016;15:216-25.

49. Huang L, Li A, Liao G, et al. Curcumol triggers apoptosis of p53 mutant triple-negative human breast cancer MDAMB 231 cells via activation of $\mathrm{p} 73$ and PUMA. 
Oncol Lett 2017;14:1080-8.

50. Ning N, Sulai L, Xiehong L, et al. Curcumol inhibits the proliferation and metastasis of melanoma via the miR-152$3 \mathrm{p} / \mathrm{PI} 3 \mathrm{~K} / \mathrm{AKT}$ and ERK/NF-kB signaling pathways. J Cancer 2020;11:1679-92.

51. Xu LC, Bian KM, Liu ZM, et al. The inhibitory effect of the curcumol on women cancer cells and synthesis of RNA. Tumor 2005;25:570-2.

52. Wang J, Chen X, Zeng JH. Effect of curcumol on proliferation and apoptosis of nasopharyngeal carcinoma cell line CNE-2. Chinese Journal of Cellular and Molecular Immunology 2011;27:790-2.

53. Wang G, Dong Y, Liu H. Curcumol enhances the antitumor effects of metformin via suppressing epithelialmesenchymal transition in triple-negative breast cancer. Ann Transl Med 2020;8:946.

54. Li S, Zhou G, Liu W, et al. Curcumol inhibits lung adenocarcinoma growth and metastasis via inactivation of PI3K/AKT and Wnt/B-catenin pathway. Oncol Res 2020. [Epub ahead of print].

55. Markowitz SD, Bertagnolli M. Molecular origins of cancer: Molecular basis of colorectal cancer. $\mathrm{N}$ Engl J Med 2009;361:2449-60.

56. Zhang K, Li MH, Huang HY, et al. Dishevelled1-3 contribute to multidrug resistance in colorectal cancer via activating $W n t / \beta$-catenin signaling. Oncotarget 2017;8:115803-16.

57. Xie W, Zhang Y, Zhang SW, et al. Oxymatrine enhanced anti-tumor effects of Bevacizumab against triple-negative breast cancer via abating $W n t / \beta$-Catenin signaling pathway. Am J Cancer Res 2019;9:1796-814.

58. Nie J, Jiang HC, Zhou YC, et al. MiR-125b regulates the proliferation and metastasis of triple negative breast cancer cells via the $\mathrm{Wnt} / \beta$-catenin pathway and EMT. Biosci Biotechnol Biochem 2019;83:1062-71.

59. Yu L, Wang CY, Pan FS, et al. HePTP promotes migration and invasion in triple-negative breast cancer cells via activation of $\mathrm{Wnt} / \beta$-catenin signaling. Biomed Pharmacother 2019;118:109361.

60. Hong CF, Chen WY, Wu CW. Upregulation of Wnt signaling under hypoxia promotes lung cancer progression. Oncol Rep 2017;38:1706-14.

61. Tai D, Wells K, Arcaroli J, et al. Targeting the WNT Signaling Pathway in Cancer Therapeutics. Oncologist 2015;20:1189-98.

62. Ravna AW, Sager G. Molecular modeling studies of ABC transporters involved in multidrug resistance. Mini Rev Med Chem 2009;9:186-93.
63. Knez L, Sodja E, Kern I, et al. Predictive value of multidrug resistance proteins, topoisomerases II and ERCC1 in small cell lung cancer: a systematic review. Lung Cancer 2011;72:271-9.

64. Shekhar MP. Drug resistance: challenges to effective therapy. Curr Cancer Drug Targets 2011;11:613-23.

65. Chen ZS, Tiwari A. Multidrug resistance proteins (MRPs/ ABCCs) in cancer chemotherapy and genetic diseases. FEBS J 2011;278:3226-45.

66. Slot AJ, Molinshi SV, Cole SP. Mammalian multidrugresistance proteins (MRPs). Essays Biochem 2011;50:179-207.

67. Reya T, Clevers H. Wnt signalling in stem cells and cancer. Nature 2005;434:843-50.

68. Cavard C, Colnot S, Audard V, et al. Wnt/beta-catenin pathway in hepatocellular carcinoma pathogenesis and liver physiology. Future Oncol 2008;4:647-60.

69. Kikuchi A, Yamamoto H, Sato A, et al. New insights into the mechanism of Wnt signaling pathway activation. Int Rev Cell Mol Biol 2011;291:21-71.

70. Lim JC, Kania KD, Wijesuriya H. Activation of betacatenin signaling by GSK-3 inhibition increases p-glycoprotein expression in brain endothelial cells. J Neurochem 2008;106:1855-65.

71. Fernández JG, Rodriguez DA, Valenzuela M, et al. Survivin expression promotes VEGF-induced tumor angiogenesis via PI3K/Akt enhanced $\beta$-catenin/Tcf-Lef dependent transcription. Mol Cancer 2014;13:209.

72. Zhang ZM, Wu JF, Luo QC, et al. Pygo2 activates MDR1 expression and mediates chemoresistance in breast cancer via the $\mathrm{Wnt} / \beta$ - catenin pathway. Oncogene 2016;35:4787-97.

73. Pedersen EA, Menon R, Bailey KM, et al. Activation of $\mathrm{Wnt} / \beta$-Catenin in Ewing Sarcoma Cells Antagonizes EWS/ETS Function and Promotes Phenotypic Transition to More Metastatic Cell States. Cancer Res 2016;76:5040-53.

74. Chen Z, Shi T, Zhang L, et al. Mammalian drug efflux transporters of the ATP binding cassette (ABC) family in multidrug resistance: A review of the past decade. Cancer Lett 2016;370:153-64.

75. Ivanyuk A, Livio F, Biollaz J, et al. Renal Drug Transporters and Drug Interactions. Clin Pharmacokinet 2017;56:825-92.

76. Keogh JP. Membrane transporters in drug development. Adv Pharmacol 2012;63:1-42.

77. Cronin-Fenton DP, Damkier P, Lash TL. Metabolism and transport of tamoxifen in relation to its effectiveness: new 
perspectives on an ongoing controversy. Future Oncol 2014;10:107-22.

78. Li Y, Yuan H, Yang K, et al. The structure and functions of P-glycoprotein. Curr Med Chem 2010;17:786-800.

79. Borst P, Evers R, Kool M, et al. A family of drug transporters: the multidrug resistance-associated proteins. J Natl Cancer Inst 2000;92:1295-302.

80. Klein DJ, Thorn CF, Desta Z, et al. PharmGKB summary: tamoxifen pathway, pharmacokinetics. Pharmacogenet Genomics 2013;23:643-7.

81. He C, Lu KL, Liu D, et al. Nanoscale metal-organic frameworks for the co-delivery of cisplatin and pooled siRNAs to enhance therapeutic efficacy in drug-resistant ovarian cancer cells. J Am Chem Soc 2014;136:5181-4.

82. Huang LZ, Wang J, Lu FT, et al. Mechanism study on anti-proliferative effects of curcumol in human hepatocarcinoma HepG2 cells. China Journal of Chinese Materia Medica 2013;38:1812-5.

83. Zang S, Tang Q, Dong F, et al. Curcumol inhibits the proliferation of gastric adenocarcinoma MGC-803 cells via downregulation of IDH1. Oncol Rep 2017;38:3583-91.

84. Chen G, Wang YH, Li MQ, et al. Curcumol induces HSC-T6 cell death through suppression of Bcl-2:

Cite this article as: Gao J, Hou D, Hu P, Mao G. Curcumol increases the sensitivity of colon cancer to 5 -FU by regulating Wnt/ $\beta$-catenin signaling. Transl Cancer Res 2021;10(5):2437-2450. doi: $10.21037 /$ tcr-21-689 involvement of PI3K and NF-kappaB pathways. Eur J Pharm Sci 2014;65:21-8.

85. Xu K, Liang X, Cui D, et al. miR-1915 inhibits Bcl2 to modulate multidrug resistance by increasing drugsensitivity in human colorectal carcinoma cells. Mol Carcinog 2013;52:70-8.

86. Wen $\mathrm{K}, \mathrm{Fu} \mathrm{Z}, \mathrm{Wu} \mathrm{X}$, et al. Oct-4 is required for an antiapoptotic behavior of chemoresistant colorectal cancer cells enriched for cancer stem cells: effects associated with STAT3/Survivin. Cancer Lett 2013;333:56-65.

87. Yan D, Deng S, Gan W, et al. Curcumol attenuates epithelial-mesenchymal transition of nasopharyngeal carcinoma cells via TGF- $\beta 1$. Mol Med Rep 2018;17:7513-20.

88. Sak K. Cytotoxicity of dietary flavonoids on different human cancer types. Pharmacogn Rev 2014;8:122-46.

89. Zhang C, Wang LM. Inhibition of autophagy attenuated curcumol-induced apoptosis in MG-63 human osteosarcoma cells via Janus kinase signaling pathway. Oncol Lett 2017;14:6387-94.

(English Language Editor: J. Chapnick) 